\title{
ESTUDIO LINGÜÍSTICO DE LOS INDICADORES DEL HUMOR. EL CASO DE LA COMEDIA DE SITUACIÓN ${ }^{1}$
}

\author{
LINGUISTICS STUDY ON HUMOR SIGNS. THE CASE OF SITCOM
}

\section{Laura $\mathbf{M}^{\mathrm{a}}$ Aliaga Aguza}

Universitat d'Alacant

Resumen

La comedia de situación es un género audiovisual que se caracteriza por crear situaciones basadas en la realidad, pero de forma humorística. En este artículo pretendemos realizar un análisis del humor verbal en este género desde un enfoque semántico - pragmático. Dicho análisis se apoya en la Teoría General del Humor Verbal (TGHV) establecida por Attardo y Raskin en 1991 y su posterior revisión realizada por Ruiz Gurillo en 2012. Para ello estudiaremos un tipo de los mecanismos humorísticos que crean el efecto cómico en la comedia de situación, concretamente analizaremos una temporada de la versión doblada al castellano de la serie estadounidense Cómo conocí a vuestra madre, centrándonos en los indicadores lingüísticos que producen humor. Además, señalaremos los principios conversacionales que se infringen en cada secuencia humorística.

PALABRAS Clave: humor verbal, indicadores lingüísticos, comedia de situación.

\begin{abstract}
The sitcom is an audiovisual genre which creates humorous reality based situations. In this paper we will try to analize verbal humor of sitcoms from a semantic- pragmatic focus. This analysis will be developed using General Theory Verbal Humor (GTVH) by Attardo \& Raskin (1991) and its review by Ruiz Gurillo (2012) as a support. To do so, we will study on one of the humorous mechanisms that creates humorous effects on sitcom, analizing a complete season of How i met your mother, and focusing in linguistic indicadors that produce humor. Also, we will point out the conversational principles infringe in each humorous sequence.
\end{abstract}

KEY WORDS: verbal humor, lingüistic indicadors, sitcom. 1 Este artículo se integra en el proyecto GENHUMID: "Género, humor e identidad” (Ministerio de Economía y Competitividad:
FFI2015-64540-C2-1-P/FECER). 


\section{INTRODUCCIÓN}

El humor es una característica del ser humano que ha existido siempre. Sin embargo ha ido variando dependiendo de épocas y culturas. Además, dentro de una sociedad una misma forma humorística puede tener diferentes funciones dependiendo del contexto, puesto que en unos contextos puede ser humorística, en otros ofensiva o, simplemente, informativa.

Por otra parte, la comedia de situación o sitcom es un género audiovisual que se caracteriza por crear situaciones basadas en la realidad, pero de forma humorística. Uno de los rasgos más sobresalientes de este género es la variedad de formas que utilizan para crear el efecto cómico, ya que dentro de este género se puede encontrar tanto humor verbal, como visual y situacional.

El objetivo de este trabajo es analizar el humor verbal que se utiliza en la comedia de situación. Para ello se examinarán exclusivamente los indicadores lingüísticos, es decir, se analizarán aquellas secuencias humorísticas que se hayan creado a partir de indicadores lingüísticos sin utilizar ningún otro mecanismo humorístico. Este análisis se llevará a cabo desde el enfoque semántico- pragmático que ofrece la Teoría General del Humor Verbal (TGHV), establecida por Attardo y Raskin en 1991 y la posterior revisión que realiza Ruiz Gurillo en 2012. La TGHV explica el humor a partir de seis recursos de conocimiento que se aplican de manera jerarquizada y, como apunta Ruiz Gurillo (2012:36):

\footnotetext{
Permite observar generalizaciones en los mecanismos lógicos que emplea el humor en sus diversas manifestaciones, contempla las estrategias narrativas como un hecho consustancial al humor y no olvida la importancia de las elecciones léxicas, gramaticales o fónicas. También concede un lugar destacado a la situación comunicativa en la que se desarrolla el texto humorístico y a quién va dirigida la burla.
}

Sin embargo, esta misma autora reflexiona sobre esta teoría y afirma que, a pesar de ser la mejor teoría lingüística que explica el humor «resulta necesario modificar o cargar de sentido y de relaciones algunos de sus recursos de conocimiento» (Ruiz Gurillo, 2012: 40). Por ello, en 2012, Ruiz Gurillo realiza una revisión de la TGHV y añade aspectos que antes se habían dejado a un lado como puede ser el registro, el género y el texto cuando se analiza la estrategia narrativa o las marcas e indicadores que se emplean en el uso del lenguaje para que un texto sea humorístico y la consecuente infracción de los principios conversacionales.

Para este estudio hemos elegido la versión doblada al castellano de la serie estadounidense Cómo conocí a vuestra madre, concretamente realizaremos un análisis cuantitativo de la segunda temporada. Según la terminología de Attardo (2008), este género entraría dentro de la categoría trama humorística, con complicación central humorística. Dicha temporada consta de veintidós capítulos de aproximadamente veinte minutos de duración cada uno. La elección de una comedia de situación estadounidense para nuestro análisis viene motivada porque las comedias españolas que hemos encontrado sufren una modificación que consideramos fundamental a la hora de crear humor, esto es, el tiempo. A pesar de que las comedias de situación españolas poseen características propias de la sitcom estadounidense como los personajes estereotipados, el capítulo cerrado, las risas enlatadas o la grabación en interiores con público en directo, se ha aumentado el tiempo de duración de cada capítulo porque está ideada para la emisión en horario de máxima audiencia. Desde nuestro punto de vista este hecho hace que transcurra más tiempo entre 
secuencias humorísticas y que dichas secuencias posean menos efecto cómico. Según apuntan Grandío Pérez y Diego González (2009: 11) refiriéndose a 7 Vidas:

Importa la estructura narrativa de la sitcom, pero con una particularidad: la adapta al tiempo medio, 50 - 55 minutos por capítulo, a diferencia de los 25 minutos de la americana. De esta manera el teaser, primer acto, desenlace y tag quedan alargados de manera a veces forzada.

A continuación nos centraremos en los aspectos más relevantes de la Teoría General del Humor Verbal (§ 2). Posteriormente, prestaremos atención a las modificaciones más importantes que propone Ruiz Gurillo (2012) de la TGHV para nuestro estudio (§ 3). Después, por un lado, analizaremos las características de la comedia de situación (§ 4); y, por otro, comentaremos tanto los rasgos característicos de los personajes principales como la trama de la serie que hemos elegido, con el fin de facilitar la comprensión de los ejemplos prácticos seleccionados para este estudio (§ 5). Luego explicaremos la metodología que hemos seguido (§ 6). Por último, mostraremos unos ejemplos seleccionados del análisis práctico (§ 7), para llegar a las conclusiones pertinentes (§ 8).

\section{TEORÍA GENERAL DEL HUMOR VERBAL}

En este apartado realizaremos una aproximación teórica a los aspectos más importantes de la Teoría General del Humor Verbal (TGHV) para nuestro análisis con el fin de que se comprenda, por un lado, la revisión posterior que realiza Ruiz Gurillo (§ 3), y por otro, nuestro análisis práctico (§ 6).

La Teoría General del Humor Verbal (TGHV) es una teoría lingüística que sirve para analizar textos humorísticos de distintas extensiones. En 1991 Attardo y Raskin realizaron una ampliación de la Teoría Semántica del Humor basada en Guiones (TSHG) establecida por Raskin ${ }^{3}$ en 1985. Dicha ampliación vino motivada porque esta no incluía todos los niveles lingüísticos y, por tanto, no servía para analizar textos más complejos que el chiste, estructura humorística prototípica. Como señala Attardo (2008: 108):

\footnotetext{
The alert reader will have noticed that the SSTH makes claims only about jokes, the simplest and least complicated type of humorous text. This methodological restriction made perfect sense for the linguist, who wanted to analyze simple cases first, but was a problem pretty much anywhere else.
}

Además, Attardo (2008: 110) resume los aspectos más importantes de la TGHV para su aplicación a textos más largos; estos son: (a) el análisis del texto como un vector, codificando cada unidad humorística según la TGHV; (b) la distinción entre ganchos y remates; (c) la importancia de la distribución relativa de las líneas del texto; y (d) una taxonomía y análisis de las tramas humorísticas. Por otra parte, la TGHV nos ayuda a precisar si un texto es humorístico o no a partir de seis recursos de conocimiento que se aplican de manera jerarquizada. Para este estudio nosotros prestaremos atención solamente a este último punto, es decir, a los seis recursos de conocimiento, puesto que vamos a realizar un análisis de secuencias humorísticas aisladas sin prestar atención a la posición que ocupan dentro del texto o a si se tratan de ganchos o remates. Ya que, como

\footnotetext{
27 Vidas fue la primera comedia de situación española. Comenzó a emitirse el 17 de enero de 1999 en Telecinco y estuvo en antena durante siete años tras quince temporadas. El argumento original fue la milagrosa recuperación de David después de permanecer dieciocho años en coma y su reincorporación a una sociedad de la que desconoce muchos aspectos. Para ello tendrá la ayuda de su hermana Carlota, su prima Laura y sus vecinos de al lado Sole y Paco.

'La Teoría Semántica del Humor basada en Guiones (TSHG) supuso un cambio en el estudio del humor verbal, puesto que se trata de una teoría que aúna tanto el complemento semántico como el pragmático, ya que señala que para estudiar el humor hay que tener en cuenta la información enciclopédica. Esta teoría se explica a partir de dos afirmaciones: a) cada texto humorístico se puede interpretar a partir de dos guiones y b) dichos guiones deben de ser opuestos. 
mencionamos en la introducción, lo que nos interesa para este artículo son los indicadores humorísticos utilizados en cada secuencia de forma independiente.

A continuación nos centraremos en la explicación de los seis recursos de conocimiento que ayudan a detectar si un texto es humorístico o no. Dichos recursos se aplican de manera jerarquizada como podemos ver en la FIGURA 1:

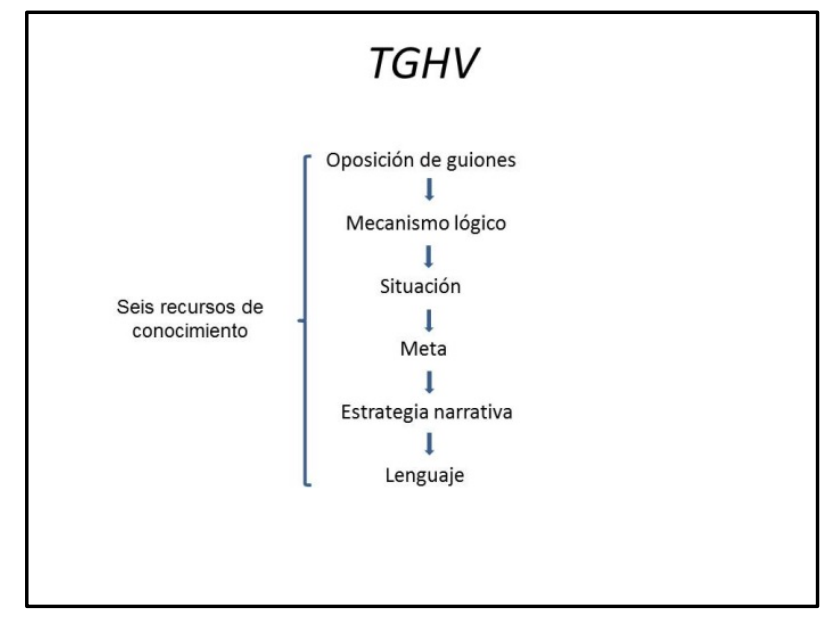

FIGURA 1: Disposición de las seis fuentes de conocimiento de la TGHV ${ }^{4}$

En primer lugar, aparece la oposición de guiones que ya encontrábamos en la TSHG. Dichos guiones son los que crean la situación humorística, es decir, la incongruencia se produce a partir de dos marcos distintos y opuestos que hacen que se cree ambigüedad y que posteriormente generará la risa en el oyente / espectador. En segundo lugar, encontramos el mecanismo lógico por el cual el humor es detectado por el receptor. Teniendo en cuenta el modelo de incongruencia - resolución, la primera fase correspondería a la fase incongruente del procesamiento de la broma mientras que el mecanismo lógico correspondería a la fase de resolución donde se explica la incongruencia detectada anteriormente. En tercer lugar, se debe tener en cuenta la situación donde se desencadena el chiste, es decir, aquellos aspectos del marco donde se desarrolla la broma que no son humorísticos. En cuarto lugar, se localizará la meta u objetivo al que va dirigido el chiste, esto es, el blanco de la broma. Se trata de un recurso de conocimiento que no se da en todas las bromas. En la comedia de situación no suele aparecer ningún personaje que sea el blanco de la broma, sino que el humor se genera a través de situaciones cómicas que se producen en escena. En quinto lugar, se analizará la estrategia narrativa, es decir, las características del género que se esté analizando. En nuestro caso, los rasgos característicos de la comedia de situación. Y, por último, el lenguaje, los elementos lingüísticos seleccionados. Siguiendo este modelo podremos determinar si un texto es humorístico. Nos parece conveniente señalar que en este artículo no tendremos en cuenta el quinto recurso de conocimiento, esto es, la estrategia narrativa, puesto que al analizar cada secuencia humorística de forma independiente, prestando atención a los indicadores lingüísticos, nos es imposibles.

Por otra parte, Attardo et alii (2002) realizan una clasificación de los mecanismos lógicos que ayudan a resolver la incongruencia (segundo recurso de conocimiento). A

4 Traducción de Ruiz Gurillo (2012: 25).

5 Para este aspecto véase Aliaga Aguza (2017). 
continuación, nos centraremos en explicar dicha taxonomía ${ }^{6}$. En primer lugar, se distingue entre mecanismos basados en relaciones sintagmáticas y mecanismos basados en razonamientos. Entre los primeros, encontramos inversiones, por un lado, y relaciones espaciales directas, por otro. Las inversiones están relacionadas con diferentes niveles de abstracción donde a través de mecanismos lingüísticos se traspasan diversos guiones y se intercambian ideas paralelas y opuestas. Dentro de las inversiones se distingue entre vacuidad, actanciales, fondo / figura y quiasmo. Por su parte, las relaciones espaciales directas se subdividen en yuxtaposición y paralelismo. Dichos mecanismos basan el efecto humorístico en la relación temporal de los guiones que se presentan en la oposición, ya sea de simultaneidad, como en el caso de la yuxtaposición, ya sea paralelística tanto explícita (aparece en el texto) como implícita (donde se llega al significado de forma inferencial). Podemos ver el resumen en la FIGURA 2.

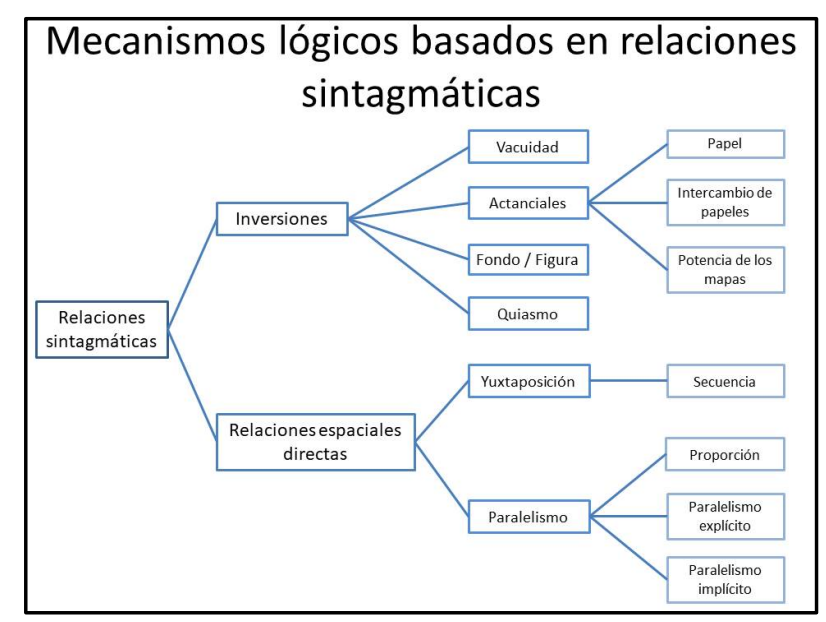

FIGURA 2: Mecanismos basados en relaciones sintagmáticas (Según Ruiz Gurillo (2012:27), basado en Attardo, Hempelmann y Di Maio, 2002: 24)

Por su parte los mecanismos lógicos basados en razonamientos se subdividen en razonamiento correcto, imperfecto y metarrazonamiento. En el razonamiento correcto se consigue humor a través de distintos procedimientos como pueden ser una falsa premisa, un enlace perdido, una situación similar, una coincidencia o una analogía, en los que se alcanza el efecto cómico partiendo de razonamientos, que desde un punto de vista estricto son correctos, pero que ignoran o limitan determinados aspectos, que al ser detectados por el receptor ponen de manifiesto la incongruencia. En el razonamiento imperfecto el emisor manipula las expectativas del receptor directamente a través de cratilismos, exageración, ignorar lo obvio, restricción del campo de aplicación o falsa analogía. Por último, los metarrazonamientos se dividen en autorreflexivo, engaño o metahumor, donde el humor aparece cuando, las expectativas creadas en el oyente de que va a escuchar un texto humorístico, son engañadas. Podemos ver un esquema en la FIGURA 3. 


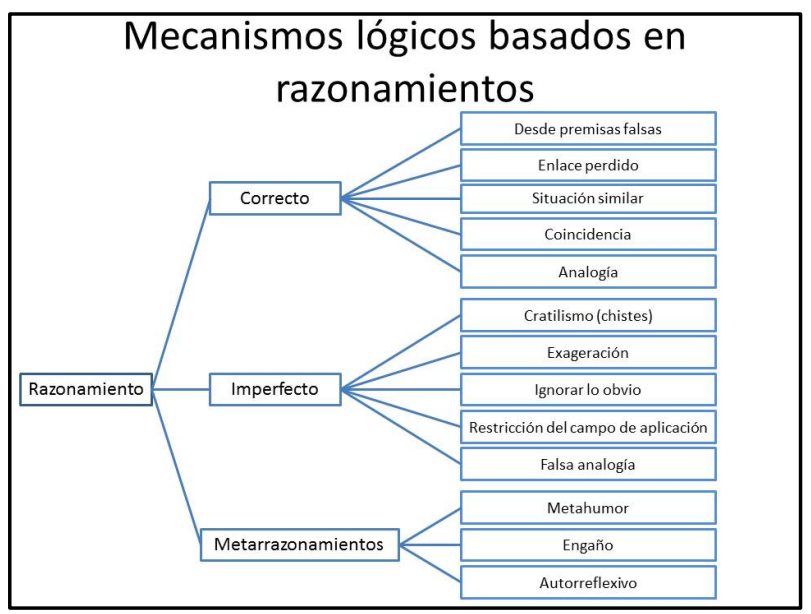

FIGURA 3: Mecanismos basados en razonamientos (Según Ruiz Grurillo (2012: 28), basado en Attardo, Hempelmann y Di Maio, 2002: 25)

Esta teoría supuso una innovación para el humor verbal. Sin embargo, no tiene en cuenta algunos aspectos como el registro, el género y el texto relacionados con la estrategia narrativa o las marcas e indicadores que facilitan la inferencia del humor en el sexto recurso de conocimiento, esto es, el lenguaje. Y la infracción de los principios conversacionales que sucede cuando un texto pasa de un modo serio a un modo humorístico. De ahí que necesitemos también apoyarnos en la revisión que realiza posteriormente Ruiz Gurillo. En el siguiente epígrafe (§ 3) comentaremos los rasgos más importantes de dicha revisión.

\section{REVISIÓN DE LA TEORÍA GENERAL DEL HUMOR VERBAL}

En las siguientes líneas realizaremos un acercamiento a la revisión que efectúa Ruiz Gurillo (2012) a la Teoría General del Humor Verbal. Esta autora en su libro La lingüística del humor en español propone modificar la relación existente entre los seis recursos de conocimiento en los que se apoya la Teoría General del Humor Verbal con el fin de que dicha teoría sirva para analizar cualquier comunicación humorística, ya sea oral o escrita, ya sea espontánea o preparada.

Esta autora, desde nuestro grupo de investigación, el Grupo GRIALE7 , desarrolla un estudio del humor desde un punto de vista lingüístico y una perspectiva pragmática, apoyándose en procesos inferenciales y fundamentado en tres aspectos (Ruiz Gurillo, 2012: 35): (a) mostrar generalizaciones en el empleo del humor; (b) observar todas las arista del fenómeno comunicativo: desde el género elegido hasta las elecciones lingüísticas pasando

\footnotetext{
7 El Grupo GRIALE según se presenta en su página web, http://griale.dfelg.ua.es/sobre-griale/ : GRIALE es el Grupo de Investigación sobre la ironía y el humor en español del Departamento de Filología Española, Lingüística General y Teoría de la Literatura de la Universidad de Alicante. Fundado en 2002, ha contado hasta el momento con cinco proyectos I+D, así como con diversas ayudas de la Universidad de Alicante. Sus objetivos principales son el análisis pragmático de la ironía y el humor, la observación de aspectos socioculturales como el género y su incidencia en la ironía y el humor, la adquisición del humor en niños y la aplicación de los resultados obtenidos a la enseñanza - aprendizaje del español como lengua extranjera y a los trastornos del lenguaje, es especial a los que tienen que ver con el espectro autista. Destacan como publicaciones conjuntas el libro de Leonor Ruiz Gurillo y Xose A. Padilla (eds.) (2009): Dime cómo ironizas y te diré quién eres. Una aproximación pragmática a la ironía. Frankfurt, Peter Lang; el trabajo colectivo del grupo GRIALE (2011): ¿Estás de broma? 20 actividades para practicar la ironía en clase de ELE. Madrid, Edinumen; y las ediciones de Leonor Ruiz-Gurillo y Mª Belén Alvarado-Ortega (eds.) (2013): Irony and Humor: From Pragmatics to Discourse. Amsterdam, John Benjamins, y de Leonor Ruiz Gurillo (eds.)(2016): Metapragmatics of humor. Current research trends, Amsterdam, John Benjamins. 
por el resto de recursos de conocimiento; y (c) analizar las marcas e indicadores como elecciones que realizan los hablantes

A continuación, nos centraremos en la modificación que propone Ruiz Gurillo (2012) a los seis recursos de conocimiento de la Teoría General del Humor Verbal con el fin de mejorarla. Dicha modificación queda plasmada en la FIGURA 4.

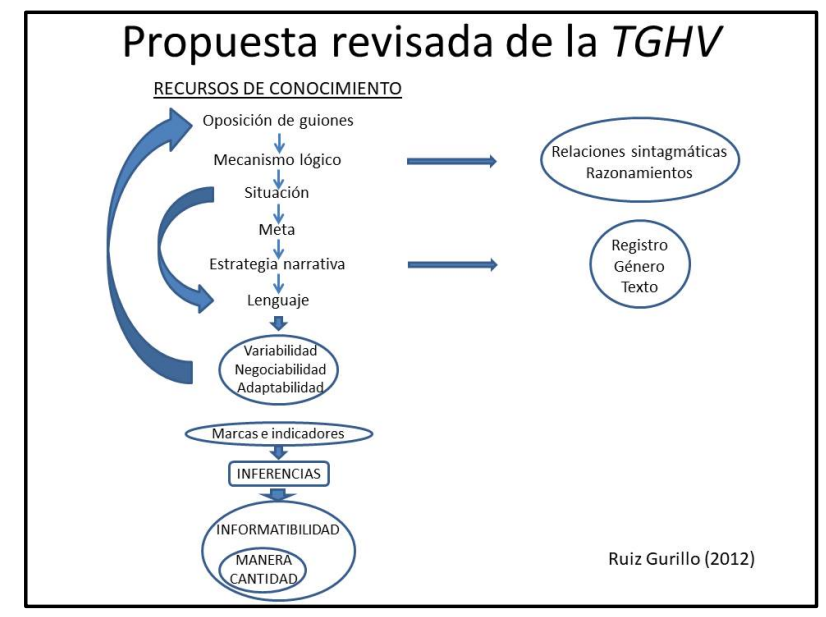

FIGURA 4: Propuesta revisada de la Teoría General del Humor Verbal (Ruiz Gurillo, 2012: 41)

Como podemos ver en la FIGURA 4, los seis recursos de conocimiento han aumentado y además están interrelacionados. En primer lugar, propone una oposición de guiones más flexible que la que aparece en la TGHV, puesto que «en el modelo no hay lugar para un espacio de mezcla donde los dos guiones alternen, sino la sustitución de un guión por otro» (Ruiz Gurillo, 2012: 37). Esta modificación viene suscitada por la diversidad de géneros textuales donde puede aparecer el humor, ya que en algunos de ellos, como pueden ser las viñetas, ambos guiones se encuentran en el mismo espacio discursivo (Padilla y Gironzetti, 2010). Además, relaciona la oposición de guiones con los conceptos de variabilidad, negociabilidad y adaptabilidad de Verschueren (2002) y el lenguaje, es decir, el emisor negocia en el contexto con todas las variables que le ofrece la lengua para adaptar su discurso para que sea lo más humorístico posible.

Por tanto, el lenguaje, a su vez, está relacionado con la situación, con las estrategias narrativas empleadas y con los mecanismos lógicos, puesto que el hablante selecciona los mecanismos necesarios para divertir al oyente teniendo en cuenta tanto el tipo de texto donde se inserta su discurso como el registro y la situación en la que se encuentra. En otras palabras, en el texto aparecen marcas e indicadores, ya sean lingüísticos o paralingüísticos, que ayudan al oyente en el proceso de inferencia humorístico. El oyente

\footnotetext{
${ }^{8}$ Para este autor el uso del lenguaje es "una continua elección lingüística". Además, "Hay tres conceptos clave necesarios para que el "hacer elecciones" tenga sentido:

La variabilidad es la propiedad del lenguaje que define la gama de posibilidades entre las que se pueden hacer las elecciones.

- La negociabilidad es la propiedad del lenguaje responsable por el hecho de que las elecciones no se hagan mecánicamente o según estrictas relaciones de forma-función, sino en base a principios y estrategias altamente flexibles.

- $\quad$ La adaptabilidad es la propiedad del lenguaje que permite al ser humano hacer elecciones lingüísticas negociables desde una gama de opciones variable de tal modo que se acerquen a grados de satisfacción de las necesidades comunicativas" (Verschueren, 2002: 129-130)
} 
capta algún elemento en el texto que incumple el principio de Informatividad (Levinson? 2004 [2000]) y desata una incongruencia. Dicha incongruencia se resuelve de forma humorística. Ruiz Gurillo (2012: 40 - 41) resume esta propuesta del siguiente modo:

\begin{abstract}
Así, junto a la propuesta inicial de la TGHV de seis fuentes de conocimiento se han añadido los mecanismos lógicos basados en relaciones sintagmáticas o en razonamientos. La estrategia narrativa, por su parte, se complementará con los aspectos relativos al registro, al género y al tipo de texto. Además, el lenguaje se entiende como variabilidad, negociabilidad y adaptabilidad de los hablantes/ escritores. Para lograr el efecto humorístico, se emplean marcas e indicadores a los que se asocian determinadas inferencias; dichas inferencias suponen, por su parte, la infracción de los principios conversacionales (Informatividad, Manera y Cantidad). Obsérvese asimismo que la oposición de guiones se materializa en las elecciones lingüísticas que se encuentran en los textos y, en consecuencia, se relacionan con marcas e indicadores. Por último, la situación está íntimamente relacionada con el lenguaje empleado.
\end{abstract}

Desde nuestro punto de vista, esta revisión es más abarcadora que la Teoría General del Humor Verbal, puesto que tiene en cuenta aspectos que dicha teoría simplemente supone, así, esta revisión nos permite seleccionar marcas e indicadores que posteriormente ayudarán para encontrar patrones generalizables a todo tipo de textos y poder analizar desde un punto de vista lingüístico el humor.

En el siguiente epígrafe nos centraremos en las características del género que estamos analizando para completar nuestra base teórica antes de explicar nuestro corpus (§ 5) y comenzar con el análisis práctico (§ 6).

\title{
4 LA COMEDIA DE SITUACIÓN
}

La sitcom o comedia de situación nace en Estados Unidos el 15 de octubre de 1951, fecha en que se estrenó I Love Lucy. Esta comedia estableció las bases de este género, ya que no ha sufrido muchas modificaciones en su formato inicial. Según apunta Álvarez Berciano (1999: 12): «Te quiero Lucy [...] fue determinante en los años para el establecimiento de la sitcom como forma reina del género, prácticamente como hoy lo conocemos». Además, hoy en día, sigue siendo un género muy productivo. Prueba de ello son la multitud de series de situación estadounidenses que se emiten actualmente y la cantidad de temporadas con las que cuenta cada una; encontramos ejemplos como Two and a Half Men (doce temporadas), How I Met Your Mother (nueve temporadas), The Big Bang Theory (doce temporadas), Mom (cinco temporadas) o Two Broke Girls (seis temporadas).

A la hora de caracterizar las comedias de situación seguiremos a Grandío Pérez y Diego González (2009). Se trata de un género humorístico que se realiza por temporadas según tenga mayor o menor acogida entre el público. Cada temporada está dividida en capítulos de duración breve, episodios de aproximadamente 22 minutos. Estos son cerrados, esto es, en cada capítulo se concluye la trama volviendo cada personaje a su estado inicial. Sin embargo, en ocasiones el final se queda abierto, preparando al espectador para el siguiente capítulo e incluso para la siguiente temporada. Los personajes de la serie son estereotipados. Las grabaciones se realizan en un estudio interior con escenarios fijos, aunque en algún capítulo especial se puede grabar alguna escena en el exterior. Ambos tipos de grabaciones se realizan con público en directo y, posteriormente, se incluyen risas enlatadas, es decir, risas grabadas con antelación que se incorporan en la cinta una vez que se ha grabado y editado el episodio completo. Los diálogos son cortos, vivos, agudos,

9 Levinson (2004 [2000]) propone tres heurísticas para aumentar la informatividad de un mensaje codificado:

HEURÍSTICA I: "lo que no se dice no está".

HEURÍSTICA II: "Io que se describe simplemente, se ejemplifica estereotípicamente".

HEURÍSTICA III: "lo que se dice de un modo inusual, no es normal; o un mensaje marcado indica una situación marcada". Así, la primera heurística correspondería al principio de Cantidad, la segunda al de Informatividad y la tercera al de Manera. Normas (ISSN: 2174-7245) | 
muy elaborados y con gags (chistes) visuales. Asimismo, suele haber unas tres tramas por capítulo, siendo una de ellas la principal.

En cuanto a la estructura, cada capítulo se divide en cinco partes bien diferenciadas. Al inicio, antes de los títulos de crédito, aparece un teaser o hook (avance). Es una parte muy breve, oscila entre uno y tres minutos, donde se muestra la trama principal. Después de los títulos de crédito se desarrolla la primera parte, donde se presentan las tramas secundarias y se desarrollan todas. Esta parte finaliza con el cliffhanger (suspense) que crea intriga antes de pasar a la publicidad. Después de esta parte, suelen aprovechar las cadenas donde se emite para pasar a la publicidad. A continuación, empieza la segunda parte. En esta parte se cierran las distintas tramas y se resuelve el conflicto del suspense de forma humorística. Al final del capítulo, después de un fondo negro, hay un tag o cola que se trata de un chiste final. La siguiente figura muestra los rasgos resumidos de la comedia de situación.

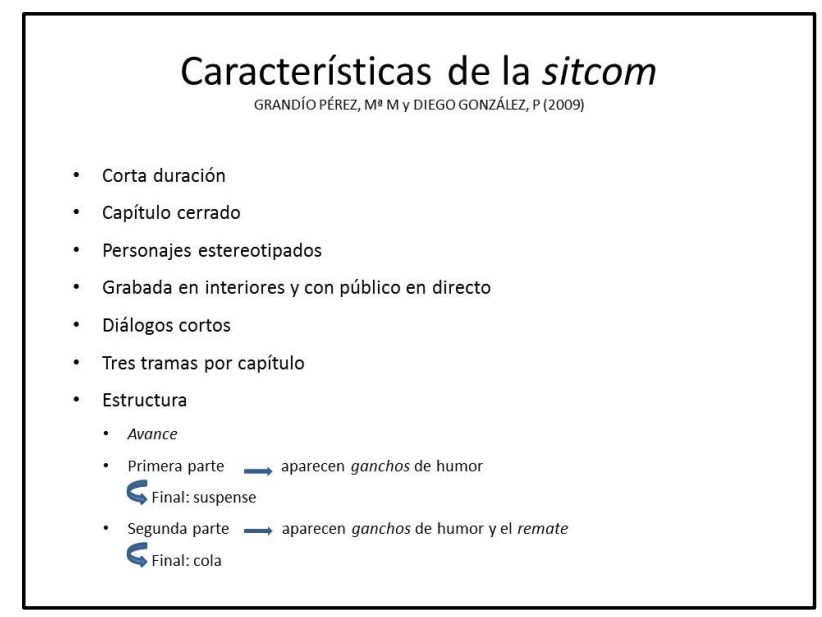

FIGURA 3: Características de la comedia de situación estadounidense

Nos parece conveniente señalar, que las sitcoms estadounidenses mantienen en gran medida los rasgos comentados. Cada capítulo de Cómo conocí a vuestra madre dura veinte minutos aproximadamente. Hay cinco personajes estereotipados. Por otra parte, se oyen risas enlatadas que se incluyen una vez que se ha grabado el episodio en el primer visionado de dicho capítulo. Cada capítulo cierra la trama, aunque, en ocasiones, esta serie no incluye un tag (cola) final y no cierra el capítulo. En la temporada analizada esto ocurre en el primer capítulo donde vemos, por medio de imágenes y música de fondo, que Lily ha regresado a la ciudad; y en el último capítulo, que nos abre la trama para la siguiente temporada.

A continuación, pasaremos a comentar tanto las características de cada personaje como el argumento de la segunda temporada de la serie elegida (§ 5) con el fin de que se comprendan mejor los ejemplos seleccionados para el análisis práctico (§ 6).

\section{NUESTRO CORPUS: LA COMEDIA DE SITUACIÓN CÓMO CONOCÍ A VUESTRA MADRE}

Cómo conocí a vuestra madre, es una comedia de situación creada por Craig Thomas y Carter Bays y producida por la CBS ${ }^{10}$. Empezó a emitirse en el año 2005 y terminó en el

${ }^{10}$ La serie se emite en la CBS estadounidense; en España en Antena 3 Neox y en Fox España; y, en Latinoamérica por el canal Fox Life. 
2014, habiéndose rodado nueve temporadas. Actualmente en España se siguen reponiendo los capítulos. El motivo de elección de esta serie se debe a que ha estado en antena muchos años, cumple las características de las comedias de situación clásica, tiene un humor blanco y va dirigida a un público en general. La trama principal de la serie versa sobre la búsqueda de Ted Mosby de su mujer ideal y las aventuras que vive junto a sus amigos hasta encontrarla. En el año 2030, Ted Mosby (interpretado por Josh Radnor) relata a sus dos hijos cómo conoció a la madre de estos. La serie comienza en el año 2005, cuando los dos mejores amigos de Ted, Marshall Eriksen (Jason Segel) y Lily Aldrin (Alyson Hannigan), se prometen. Además de estos tres personajes, aparecen otros dos personajes principales como son Robin Scherbatsky (Cobie Smulders), la chica de la que Ted está enamorado, y Barney Stinson (Neil Patrick Harris), un soltero empedernido amigo de Ted.

La trama de la segunda temporada arranca en el verano del 2006 en el momento en que Lily abandona a Marshall para ir a vivir su sueño de convertirse en una pintora famosa en San Francisco antes de casarse, mientras Ted y Robin acaban de empezar una relación seria. A lo largo de la segunda temporada vemos cómo evoluciona la vida de cada uno de los personajes en su nueva faceta. Después de varios meses y de la vuelta de Lily a la ciudad, Marshall y Lily comienzan de nuevo su relación y se comprometen de nuevo. Durante este tiempo, Barney sigue aumentando la lista de sus conquistas amorosas. Por su parte, la relación de Ted y Robin es cada vez más seria, incluso se plantean vivir juntos. La temporada termina en mayo de 2007 con la boda de Lily y Marshall y con la ruptura de Ted y Robin, puesto que tienen intereses diferentes. De este modo, Barney volverá a tener a su compañero Ted para ligar.

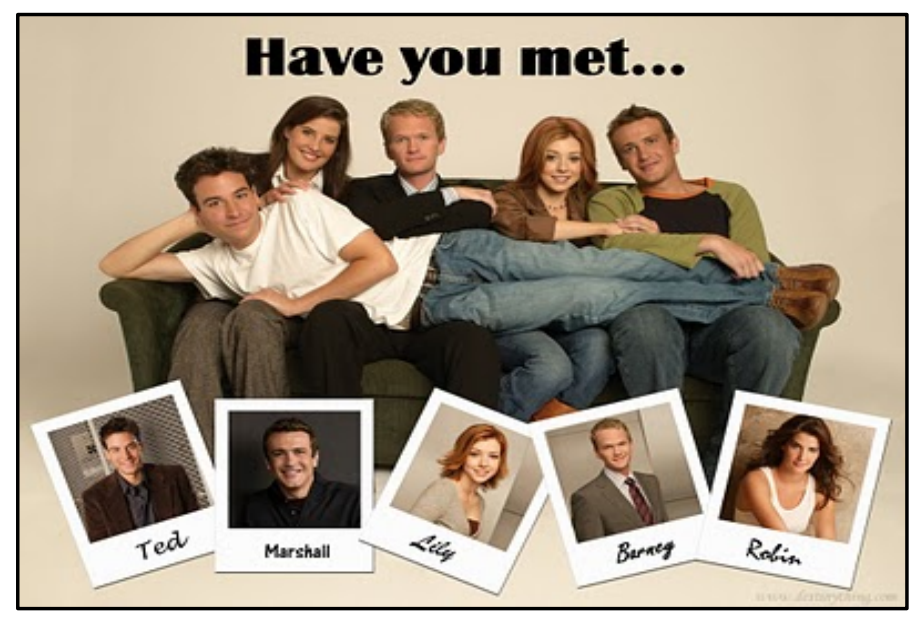

FIGURA 611: Personajes principales de Cómo conocí a vuestra madre

A continuación, nos centraremos en los rasgos del corpus seleccionado para nuestro análisis.

\subsection{Corpus y Metodología}

En este apartado señalaremos las características generales de nuestro corpus y la metodología que hemos llevado a cabo.

${ }^{11}$ La imagen se puede encontrar en http://www.todofondosdeseries.com/category/como-conoci-a-vuestra-madre/page/2 Normas (ISSN: 2174-7245) | 
Para preparar nuestro corpus de estudio hemos realizado un análisis cuantitativo de los veintidós capítulos que componen la segunda temporada de Cómo conocí a vuestra madre. Para ello hemos dividido cada capítulo en secuencias humorísticas basándonos en las risas enlatadas y en el sentido del diálogo. Entendemos por secuencia humorística aquella estructura que posee una unidad temática. Por lo que si en el texto aparecían risas enlatadas, pero la conversación se quedaba en suspenso, cortábamos el fragmento donde la conversación estaba dotada de sentido. De este modo, hemos encontrado 1431 secuencias diferentes. Dichas secuencias las hemos dividido en humor verbal, humor audiovisual, humor situacional o mezcla de alguno de ellos. Así, aparecen 506 casos de humor verbal, lo que corresponde a un 35.36\%. De esos 506 casos de humor verbal en 20 se utilizan solo indicadores lingüísticos sin ningún otro mecanismo humorístico más, lo que corresponde a un 4\%. Entre esos 20, hay 10 en los que se utilizan exclusivamente un indicador, lo que corresponde a un $0.70 \%$, un porcentaje muy bajo, puesto que este género se caracteriza por la utilización de distintos mecanismos humorísticos de manera simultánea, es decir, lo que funciona en la comedia de situación es la multimodalidad. De este modo, hemos encontrado cinco indicadores lingüísticos diferentes. Este recurso no se utiliza en todos los capítulos de la temporada, solo lo encontramos en ocho de ellos ${ }^{12}$. Además, nos parece conveniente señalar que no se produce en todas las partes de los capítulos. Solo aparece en la primera y en la segunda parte, concretamente, hay cuatro casos en la primera parte y seis en la segunda parte de los capítulos.

En cuanto a los indicadores lingüísticos, procedimientos de por sí humorísticos, que se repiten a la hora de crear humor a través de un único indicador son en orden de mayor a menor utilización equívoco, unidades fraseológicas de uso canónico, figura retórica: comparación, pseudoabarcador y formación de palabras: invención de palabras: creación afijal.

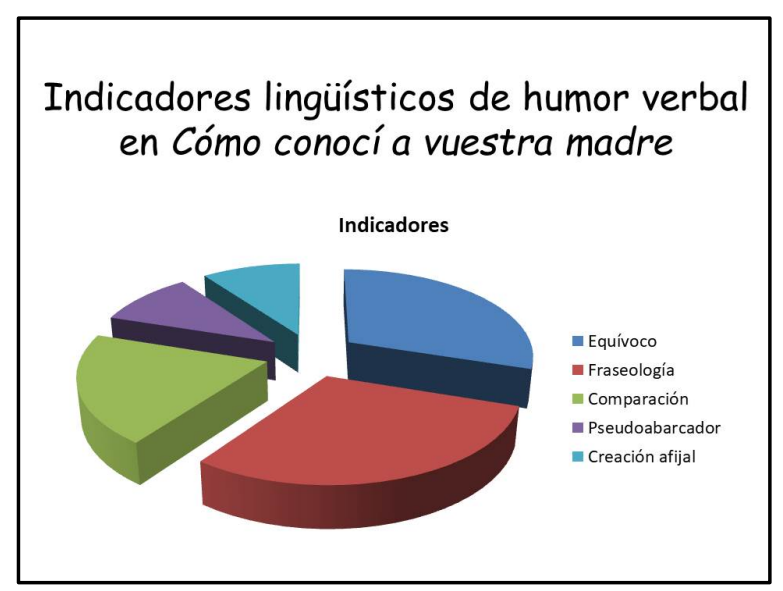

FIGURA 7: Indicadores lingüísticos de humor verbal en Cómo conocí a vuestra madre

A continuación, nos centraremos en el análisis de los indicadores lingüísticos utilizados para crear humor verbal exclusivamente a través de un único indicador que hemos encontrado en la segunda temporada de la comedia de situación Cómo conocí a vuestra

12 El humor verbal que se produce exclusivamente por medio de un único indicador lingüístico lo hemos encontrado en los capítulos cuatro, nueve, trece, catorce, quince, dieciséis, diecisiete y dieciocho. 
madre, con el fin de establecer las conclusiones pertinentes del uso de dichos indicadores en la serie analizada.

\section{ANÁLISIS}

En este epígrafe analizaremos cada uno de los cinco indicadores diferentes que hemos encontrado que se repiten en la segunda temporada de Cómo conocí a vuestra madre en el humor verbal que se consigue a través del uso de un solo indicador lingüístico, a saber, el equívoco, la unidad fraseológica de uso canónico, la figura retórica: comparación, el pseudoabarcador y la formación de palabras: invención de palabras: creación afijal.

Para empezar, distinguiremos entre marca e indicador y ofreceremos una definición de cada uno de ellos. Para ello seguiremos al grupo GRIALE. Este grupo, a la hora de diferenciar entre marca e indicador, parte de su función (Padilla García, 2009: 147). En primer lugar, veremos las características que posee la marca: posee un valor procedimental, es decir, las marcas ayudan a identificar el humor, pero no poseen humor por sí mismas. Simplemente sirven de señal al oyente, funcionando como guías, al advertir que un enunciado tiene significado humorístico. Sin embargo, estas marcas no explican cómo se tiene que entender el humor, solo ayudan en su interpretación, favoreciendo la comprensión de los enunciados humorísticos. Por su parte, el indicador produce o contiene humor por sí mismo, es decir, son los responsables directos del enunciado humorístico. Es una manera especial de enunciar que permite al oyente entender el funcionamiento del humor, interpretando dicho enunciado de manera humorística.

Resumiendo, entendemos por marca aquello que ayuda a crear el efecto humorístico, sirviendo de pista para inferir el humor, pero no es humorístico en sí mismo, mientras que indicador es un procedimiento por sí mismo humorístico. No obstante cabe matizar, como apunta Ruiz Gurillo (2012: 117):

\footnotetext{
Tanto las marcas como los indicadores son recursos lingüísticos comunes que aceptan, por lo general, una interpretación recta, pero en contextos irónicos se convierten en pistas fiables que ayudan al oyente / lector en la interpretación.
}

En otras palabras, las marcas e indicadores funcionarán como tales en contextos humorísticos, donde el emisor quiere hacer un uso especial del lenguaje orientando el enunciado para tal fin.

Para explicar cada ejemplo, como mencionamos en la introducción de este artículo, nos basaremos tanto en cinco de los recursos de conocimiento que establece la Teoría General del Humor Verbal, como en la revisión posterior realizada por Ruiz Gurillo para el humor en español, teniendo en cuenta otros aspectos como los indicadores lingüísticos y la infracción de los principios conversacionales. Para ello, en primer lugar, explicaremos la situación para que el lector se sitúe en la escena donde se genera el humor, esto es, el tercer recurso de conocimiento. En segundo lugar, expondremos el ejemplo marcando en negrita el indicador humorístico. Después del ejemplo, explicaremos cómo funciona el indicador que estamos analizando, por un lado; y estableceremos tanto la oposición de guiones (recurso 1) como el mecanismo lógico (recurso 2), por otro. Además, señalaremos la meta (recurso 4) en el caso en que haya un personaje en el que recaiga la burla directamente y no se trate simplemente de una situación incongruente dentro de las expectativas creadas por el espectador. Por último, prestaremos atención al principio conversacional que se infringe en cada caso. Además, también señalaremos hacia quién va dirigida la secuencia humorística, ya que en unas ocasiones va dirigida únicamente hacia 
el espectador y en otras tanto hacia el espectador como hacia los protagonistas de la comedia de situación. Nos parece conveniente recordar que en este artículo no analizaremos la estrategia narrativa, porque al tratarse de la estructura del género, se debe analizar de forma global, puesto que es la estructura en su conjunto la que crea el efecto cómico, esto es, la trama argumentativa de cada capítulo evoluciona a través de ganchos de humor, bromas menores que sitúan al espectador en la trama creando falsas premisas en el oyente. Estos ganchos preparan el argumento para aumentar el giro humorístico del remate final. El remate se encuentra casi al final de la segunda parte y es el giro humorístico más importante de todo el capítulo, puesto que hace que todo se restablezca y vuelva a la normalidad. Nosotros realizaremos el análisis de secuencias humorísticas de forma independiente sin prestar atención a este aspecto, puesto que nuestro objetivo es analizar exclusivamente los indicadores lingüísticos que forma parte de secuencias humorísticas verbales.

A continuación, ofreceremos un ejemplo de cada uno de los cinco indicadores lingüísticos que crean el efecto cómico en las secuencias humorísticas verbales, esto es, equívoco, unidad fraseológica de uso canónico, figura retórica: comparación, pseudoabarcador y formación de palabras: invención de palabras: creación afijal.

\subsection{Indicador lingüístico: equívoco}

El primer indicador lingüístico es el que hemos denominado equívoco. Bajo este término ubicamos todos aquellos errores lingüísticos que comete alguno de los personajes de la comedia de situación a la hora de hablar, sea de forma intencionada o no intencionada. Por medio de este indicador aparece una incongruencia porque el hablante no dice lo que debería haber dicho. El oyente detecta dicho equívoco, lo interpreta de forma humorística y surge la risa. Debemos aclarar que se trata exclusivamente de errores lingüísticos, ya que otro tipo de errores, por ejemplo situacionales, no se incluyen aquí. Este indicador, junto a la unidad fraseológica, es el más utilizado para crear el tipo de humor que estamos analizando.

A continuación, pasaremos a analizar el ejemplo seleccionado, (1), para el indicador lingüístico que hemos denominado equívoco. En primer lugar, nos centraremos en el recurso tres que establece la Teoría General del Humor Verbal, esto es, la situación. Es el domingo que se celebra la Súper Bolw y los cinco amigos han decidido verla juntos en casa de Ted y Marshall. Mientras están ultimando los preparativos en el bar que frecuentan, el MacLarens, se enteran de que ha fallecido Mark, un hombre muy querido y conocido en dicho bar. Los protagonistas no pueden verla porque se ven obligados a asistir al funeral de Mark, ya que ambos acontecimientos son a la misma hora. Sin embargo, los chicos no saben quién es Mark simplemente por el nombre, pero si no acuden al funeral no podrán volver al bar que tanto les gusta, puesto que acaban de presenciar cómo el camarero ha echado a un cliente del bar y le ha prohibido la entrada debido a que este ha decidido no ir al funeral a causa de preferir ver el partido de la Súper Bowl. Como vemos la secuencia ya parte de una situación humorística.

(1) Ted: Muy bien, este es el plan, grabamos el partido, damos nuestro adiós a Mat.

Lily: Mark.

(Primera parte del capítulo catorce).

En este caso, (1), el humor aparece de forma verbal a partir del equívoco de Ted hacia el nombre del fallecido. El indicador equívoco actúa como procedimiento lingüístico que crea humor en sí mismo, ya que la confusión de un nombre por otro es la causante del efecto 
hilarante. El hablante, Ted, confunde el nombre del fallecido. Este hecho produce incongruencia en el espectador, puesto que unas escenas antes han estado hablando de él. El oyente, el público, detecta dicha incongruencia, el hecho de no conocer al fallecido, y aparece la risa. La oposición de guiones, primer recurso de conocimiento, es CONOCIDO / DESCONOCIDO. En este ejemplo aparecen dos marcos opuestos que juegan con la ambigüedad semántica para crear una incongruencia humorística, esto es, un funeral es una celebración íntima que se realiza para dar el último adiós a una persona querida. Sin embargo, se rompe el esquema al comprobar que el protagonista de la serie ni siquiera puede recordar el nombre del fallecido. El segundo recurso de conocimiento, el mecanismo lógico, está basado en un razonamiento correcto desde una premisa falsa, ya que cuando se asiste al funeral de una persona lo lógico es conocer al fallecido y mostrar interés hacia él o, al menos, hacia sus familiares. No obstante, en este caso, Ted y sus amigos no conocen al fallecido, pero asisten al funeral por intereses personales.

En cuanto a los principios conversacionales que se infringen en esta secuencia humorística son tanto el principio de Cantidad como el principio de Informatividad. Cuando Ted confunde el nombre del fallecido, se oculta al espectador la información de que no conocen a Mark, es decir, no se está ofreciendo toda la información necesaria. Esa ocultación hace que se cree ambigüedad en el oyente, ya que si han decidido asistir al funeral es porque se han acordado de quién es el fallecido y no porque quieran volver a la cervecería que les gusta siempre que lo deseen. Por último, nos parece conveniente señalar que esta secuencia humorística va dirigida únicamente al espectador, puesto que los personajes de la serie no ríen tan el indicador lingüístico. Simplemente corrigen al hablante e ignoran el hecho de que se ha equivocado de nombre, puede ser debido a que ven normal que confunda el nombre debido a que ellos tampoco conocen al fallecido.

Este indicador lingüístico, el equívoco, se repite a lo largo del capítulo catorce, ya sea funcionando solo o junto a otros indicadores y marcas humorísticos. Cada vez que el protagonista hace referencia al fallecido menciona distintos nombres antes que Mark. Incluso al final del episodio, en el año 2030, Ted, voz en off, hace una reflexión de lo sucedido en aquella historia y reconoce que hoy en día se sigue equivocando de nombre.

\subsection{Indicador lingüístico: unidad fraseológica: uso canónico}

El siguiente indicador es una unidad fraseológica de uso canónico. Las unidades fraseológicas son sintagmas u otras unidades estructurales superiores que poseen dos propiedades: la fijación y la idiomaticidad. Siguiendo a Ruiz Gurillo (2001: 22), comprendemos que un sintagma es fijo cuando sus componentes muestran una estabilidad que se refleja en las dificultades para variarlos, modificarlos, sustituirlos o suprimirlos; e idiomático, cuando la interpretación del sintagma no se obtiene de la suma de sus partes, tomadas por separado o en su conjunto. Aunque esta propiedad no se da en igual grado en unas unidades que en otras. Las unidades fraseológicas son un recurso muy productivo a la hora de crear humor, ya que se suele jugar con el significado literal y con el significado idiomático para crear ambigüedad y producir humor. Como hemos mencionado en el apartado anterior, la fraseología junto con el equívoco son los indicadores lingüísticos más recurrentes para realizar este tipo de humor.

Para el análisis del siguiente ejemplo, (2), primero comentaremos la situación, esto es, el tercer recurso de conocimiento. El coche de Marshall, el Fiero, se ha estropeado un kilómetro antes de llegar a los doscientos mil kilómetros, un acontecimiento que estaban esperando todos los personajes con mucha ilusión. Ted y Marshall llevan al coche al taller. 
El resto de personajes principales también acuden al taller. Mientras esperan en la sala para saber el diagnóstico, los protagonistas cuentan distintas aventuras que han pasado cada uno de los personajes en el coche. Durante todo el capítulo se realiza un símil como si el taller fuese un hospital y el coche una persona enferma, esta oposición de guiones vertebra el humor de todo el capítulo. Ted y Marshall son los primeros en contar una anécdota que vivieron con el coche. Ambos chicos vivían en el campus de la universidad. En las primeras vacaciones compartieron coche en su regreso a casa para reducir gastos. Sin embargo, terminaron pasando la noche juntos en el coche, porque se desviaron por un camino incorrecto y se perdieron. Dicha noche pensaron que iban a morir congelados debido al frío que hacía fuera, por lo que decidieron pasar toda la noche abrazados.

(2) Ted: $Y$ fue en aquel viaje cuando Marshall y yo nos hicimos amigos.

Marshall: Sí.

Barney: $Y$ con privilegios, por lo visto.

(Primera parte del capítulo diecisiete).

En (2) el humor aparece a partir del comentario jocoso que realiza Barney sobre la noche en que Ted y Marshall se hicieron amigos. A través de la expresión "hacerse amigos" que utiliza Ted, Barney se la lleva al plano sexual al añadirle "con privilegios". De este modo, se ha servido de una expresión sin marcar y la ha convertido en una unidad fraseológica, es decir, en una expresión marcada y humorística. En este ejemplo, el primer recurso de conocimiento, la oposición de guiones es SUPERVIVENCIA / SEXUALIDAD. El hablante ha jugado con la ambigüedad que crea la unidad fraseológica y la situación contada anteriormente por los protagonistas. Encontramos dos marcos enfrentados, esto es, abrazarse para darse calor o abrazarse para satisfacerse sexualmente. A través de esta oposición, el hablante, Barney, utiliza la expresión "hacerse amigos" con su significado idiomático y no con el significado literal y, así, se produce el humor. El segundo recurso de conocimiento, el mecanismo lógico, está basado en un razonamiento correcto, desde premisas falsas, ya que Ted y Marshall estaban abrazos para mantener sus cuerpos calientes y no morir congelados. Sin embargo, Barney parte de la idea de que se abrazaban para otros fines, como son los sexuales.

En este caso el principio que se infringe es el de Manera y el de Informatividad. El principio de Manera se incumple, puesto que con el uso de la fraseología se marca el discurso y se convierte en humorístico. En este caso debido a que se ha utilizado el significado idiomático al matizar "con privilegios". Este hecho crea ambigüedad semántica en el oyente con lo que también afecta al principio de Informatividad. Por último, esta secuencia humorística va dirigida tanto al espectador como a los personajes de la serie. Barney, de manera intencionada, destaca que se trata de amigos con privilegios para llamar la atención de sus amigos y cambien el modo de la conversación a humorístico.

\subsection{Indicador lingüístico: figura retórica: comparación}

El siguiente indicador que comentaremos es la figura retórica: comparación. Siguiendo al diccionario de términos literarios (Platas Tasende, 2004: 152) desde un punto de vista retórico entendemos por comparación «aquella relación de semejanza entre un término real y un término imaginario - enaltecedor o degradante - con el que el primero es comparado". Cuando esta comparación es totalmente inesperada y se produce una incongruencia se convierte en humorística. Es decir, aparecen dos o más términos que en situaciones no humorísticas no tienen ninguna característica en común que pueda ser comparable y se busca una relación de semejanza no esperada e, incluso, ilógica para crear la hilaridad. 
Según apunta Gallud Jardiel (2016: 129): «a mayor disparidad entre los términos comparados, mayor comicidad».

La situación, tercer recurso de conocimiento, en el ejemplo (3) es la siguiente: Lily ha invitado a sus amigos a una obra de teatro donde ella actúa. Desde el primer momento Barney no quería ir, porque es de la opinión de que a un amigo no se le invita a esas cosas. Sin embargo, finalmente termina yendo junto al resto de amigos. Durante toda la obra, Barney ha realizado gestos indicando que la obra no le estaba gustando nada. La obra ha sido bastante mala. A pesar de ello, cuando termina todos sus amigos se acercan a felicitarla. Sin embargo, Barney le dice que ha sido malísima.

(3) Marshall: Barney.

Barney: ¿Qué? Ha sido horrible, vamos estáis de acuerdo conmigo, ¿verdad? Oye, lo siento, solo estoy siendo sincero porque somos amigos.

Lily: No, los amigos hacen sentirse bien unos a otros, se complementan y se apoyan, en eso consiste ser un buen amigo.

Barney: Sí, si eres un pitufo.

(Primera parte del capítulo dieciséis).

El humor aparece de forma verbal a través de la comparación que realiza Barney sobre Lily y un pitufo ${ }^{13}$. Dicho humor se interpreta por dos vías diferentes: por la personalidad de los pitufos y por el tamaño. Esto es, por un lado, puesto que los pitufos son siempre buenos unos con otros y no como en la sociedad actual que algunas personas, como Barney, normalmente buscan su propio beneficio -aunque en este caso haya sido sincero. Y, por otro, ya que Lily es bajita y Barney lo recuerda en distintos episodios de la serie. La elección de la palabra "pitufo" es la que hace que la conversación cambie a modo humorístico, debido a que con dicha palabra aúna dos rasgos de la protagonista, esto es, su tamaño pequeño y la bondad entre los amigos que le está demandando en ese momento. En este caso, la oposición de guiones, primer recurso de conocimiento, es HUMANO / PITUFO. El hablante ha creado dos marcos enfrentados que hacen que aparezca la incongruencia y el desenlace humorístico. Lily está pidiendo a Barney que se comporte de una forma que para él es irreal. De ahí que la comparación sea con un pitufo y no con otra entidad que se pueda situar en el plano de la realidad. El mecanismo lógico, segundo recurso de conocimiento, es un razonamiento imperfecto basado en una falsa analogía, ya que los pitufos y los seres humanos no poseen ninguna característica en común. Se trata de dos entidades que no se pueden comparar.

El principio que se infringe es el de Informatividad. A través del término "pitufo", seres pequeños y siempre buenos, se crea ambigüedad semántica y se ofrece más información de la requerida. Por otra parte, en este caso, el oyente debe conocer las características generales de los pitufos para que el humor llegue a buen término. Esta secuencia humorística está dirigida exclusivamente a los espectadores, ya que los protagonistas de la serie están viviendo un momento de tensión debido a la sinceridad de su amigo. Otros personajes, como son Ted y Robin, también opinan lo mismo. Sin embargo, las reglas sociales establecidas hacen que no sean sinceros con su amiga para no hacerla daño. Por su parte, Marshall está encantado.

\footnotetext{
${ }^{13}$ Los Pitufos son seres animados creados por Peyo originariamente para historietas de periódico, aunque posteriormente se adaptó a otros medios como son el cine y la televisión. Son personajes caracterizados por ser bondadosos, pequeños y azules. 


\subsection{Indicador lingüístico: pseudoabarcador}

El siguiente indicador que analizaremos es el pseudoabarcador. Se trata de un procedimiento lingüístico que siempre se utiliza con fines humorísticos o irónico humorísticos. Este hecho no ocurre con los indicadores anteriores, ya que tanto la fraseología como la comparación y el equívoco pueden funcionar tanto en un discurso en modo humorístico como en un discurso en modo no humorístico. Con el pseudoabarcador se forma una categoría nueva con los elementos que se enumeran en la secuencia humorística, la unión de dichos elementos es incongruente y se crea humor. El pseudoabarcador, según Timofeeva (2012: 136): «es un indicador de la ironía y / o el humor que consiste en crear una clase semántica formada por diversos elementos integrados en la misma que no lo agotan, pero que se reinterpretan como si lo hicieran», es decir, este indicador consiste en crear una lista de elementos que no poseen las mismas características para formar dicha lista, pero que se integran como sí las poseyeran. De ese modo se crea la incongruencia humorística. Cuando el oyente reconoce elementos que en otro momento no los seleccionaría bajo los mismos rasgos, aparece la risa.

En (4) la situación, el tercer recurso de conocimiento que establece la Teoría General del Humor Verbal es la siguiente: Marshall lleva entrenando varios meses para participar en el maratón de Nueva York de ese año. Para ayudar a Marshall en su entrenamiento, Lily le está leyendo un libro en voz alta al mismo tiempo que este entrena con el fin de que mejore su rendimiento.

(4) Lily: Pueden aparecer rozaduras o ampollas en numerosas áreas, incluyendo los pies, las axilas o incluso los pezones, aplíquese un poco de vaselina en las zonas afectadas.

(Segunda parte del capítulo quince).

En (4) el humor aparece al escuchar que por correr pueden salir ampollas en los pezones. A través del pseudoabarcor se crea una clase ad hoc donde la unión de los elementos extraños es la que produce el efecto humorístico. El autor ha creado una lista con partes del cuerpo que se pueden deteriorar al correr. Sin embargo estos elementos se escapan de la lógica, ya que los pezones no son una parte que sufra ningún daño al hacer deporte. Los pezones pueden sufrir daño, por ejemplo, cuando se amamanta a un bebé. De ahí que la oposición de guiones que hemos establecido, primer recurso de conocimiento, sea CORREDOR / MATERNIDAD. En este caso, por un lado tenemos un guión relacionado con el deporte, donde un corredor entrena muchas horas al día y, debido al roce de unas partes del cuerpo con otras, se pueden sufrir heridas. Por otro lado, encontramos el guión relacionado con la maternidad, una mamá reciente amamanta a su bebé muchas horas al día, por lo que puede sufrir grietas y ampollas en el pecho a causa de la succión del bebé. En este caso se ha relacionado los daños que pueden sufrir los corredores con los daños que pueden sufrir las madres que acaban de tener un bebé y se han unido para crear el efecto hilarante deseado. El segundo recurso de conocimiento, el mecanismo lógico aparece de forma verbal apoyado en un razonamiento imperfecto, concretamente, en una exageración. Se han buscado dos situaciones que no están relacionadas, esto es, un deportista, concretamente un corredor, y una mamá reciente. Se ha utilizado uno de los rasgos más sobresalientes de la segunda para llevar la primera situación al extremo. De este modo, se han marcado zonas del cuerpo muy difíciles de deterior al correr, puesto que no se encuentran en contacto con ninguna otra zona para que salgan rozaduras o ampollas. Así, se ha obtenido la incongruencia y el humor. 
En este caso el principio que se infringe es el de Informatividad, ya que al unir elementos de diferente naturaleza como son los pies, las axilas y los pezones, se ofrece más información de la necesaria, puesto que el razonamiento sale de la lógica del oyente. La unión de dichos elementos es incongruente y se crea ambigüedad consiguiendo un efecto cómico. Por último, esta secuencia humorística va dirigida únicamente hacia el espectador. El autor de la broma utiliza el pseudoabarcador para que el espectador ría, pero que los personajes de la serie, concretamente Marshall y Lily, lo tomen interpreten de forma no humorística, como han interpretado todas las demás recomendaciones del libro.

\subsection{Indicador lingüístico: formación de palabras: invención de palabras: creación afijal}

El último indicador lingüístico que hemos encontrado en el análisis del humor verbal creado a partir de un único indicador es el que hemos denominado formación de palabras: invención de palabras: creación afijal. Al igual que ocurre en el caso anterior, se trata de un procedimiento lingüístico que siempre se utiliza de forma humorística. Este indicador consiste en crear nuevos términos añadiendo diferentes afijos a una base léxica, con el fin de que el término resultante sea una combinación de varios elementos que consiga un efecto hilarante.

En las siguientes líneas analizaremos el ejemplo seleccionado para el último indicador lingüístico que trataremos en este artículo. En primer lugar explicaremos la situación de dicho ejemplo (5), tercer recurso de conocimiento. Ted acaba de conseguir dirigir un proyecto muy importante. Este hecho hace que le robe el puesto a su antiguo jefe, el señor Draders, y este quede bajo la supervisión de Ted. En esa misma época el señor Draders se queda sin casa, puesto que su mujer le ha echado. Este estaba viviendo en la oficina y cuando Ted se entera se ve obligado a invitarle unos días a dormir en su casa. Al igual que ocurre en el primer ejemplo se parte de una situación incongruente, ya que Ted es el que le ha arrebatado el puesto a Draders y, además, como no trabaja como debe, tiene que despedirle. En vez de eso, le invita a su casa. Por lo tanto van juntos todos los días al trabajo.

(5) Ted: Ese taxista no se callaba.

Draders: Sí, deberíamos llamarlo charlista.

(Segunda parte del capítulo trece).

Aquí encontramos humor a través de la palabra que se inventa Draders. Dicha palabra tiene sentido por la frase introductoria de Ted "ese taxista no se callaba». Un taxista que habla mucho > hablador, de forma coloquial > charlador. De ahí «charl - ista». Se ha utilizado la raíz del término coloquial "charlador»: Charl- y se le ha añadido el sufijo -ista, utilizado para la creación de profesiones. Por tanto la oposición de guiones, primer recurso de conocimiento, es TAXISTA / CHARLADOR, donde se ha creado una profesión nueva a partir de la primera para designar a una persona que se dedica profesionalmente a hablar. El segundo recurso de conocimiento, el mecanismo lógico está basado en un razonamiento imperfecto, es un cratilismo. A partir de un mecanismo habitual de creación de palabras como es la sufijación, se ha creado un nuevo término, concretamente una nueva profesión, la de charlador, con fines humorísticos. Además, es el único caso de los cinco analizados en este artículo donde aparece la meta o el blanco de la broma, cuarto recurso de conocimiento, el taxista.

En este caso se infringen dos principios el de Manera y el de Informatividad. En primer lugar el principio de Manera puesto que a través del término inventado se marca el discurso. Además, el procedimiento convencional de creación léxica para la formación de Normas (ISSN: 2174-7245) | 
profesiones añadiendo el sufijo -ista, crea ambigüedad al unirlo a la base Char-, de este modo, en segundo lugar, se incumple el principio de Informatividad. Por último, esta secuencia humorística va dirigida tanto al oyente como al espectador, ya que la intención del hablante es la realización de un chiste por medio del término inventado con el fin de divertir a la audiencia.

Una vez realizado el análisis de los cinco indicadores lingüísticos que se utilizan para crear humor verbal a través de exclusivamente un único indicador, sin recurrir a otro recurso humorístico, pasaremos a establecer las conclusiones pertinentes (§ 7).

\section{CONCLUSIONES}

El objetivo de este artículo ha sido analizar el humor verbal que se utiliza en la comedia de situación a través del uso de indicadores lingüísticos, es decir, se han analizado aquellas secuencias humorísticas que se han creado por medio de indicadores lingüísticos sin utilizar ningún otro mecanismo humorístico como puede ser marcas tanto lingüísticas como extralingüísticas.

Este análisis se ha realizado a través del enfoque semántico - pragmático que nos ofrecen las dos teorías en las que nos hemos basado, esto es, la Teoría General del Humor Verbal establecida por Attardo y Raskin en 1991 y su posterior revisión realizada por Ruiz Gurillo para la lingüística del humor en español en 2012.

Para este estudio hemos realizado un análisis cuantitativo la segunda temporada de la comedia de situación estadounidense Cómo conocí a vuestra madre. De este modo hemos obtenido 506 casos de humor verbal, lo que corresponde a un $35.36 \%$. El resto de casos son de humor audiovisual, humor situacional o mezcla de alguno de ellos. De esos 506 casos de humor verbal en 20 se utilizan solo indicadores lingüísticos sin ningún otro mecanismo humorístico más. Entre esos 20, hay 10 en los que se utiliza exclusivamente un indicador. Así, hemos encontrado 5 indicadores lingüísticos diferentes.

En conclusión, en la comedia de situación hay pocas secuencias humorísticas que se realicen únicamente con elementos lingüísticos como son los indicadores, porque lo que funciona en este género es la multimodalidad, es decir, para crear el efecto cómico en este tipo de comedias se mezclan diferentes recursos humorísticos tanto verbales, como audiovisuales y situacionales. Aun así, hemos encontrado indicadores lingüísticos que funcionan de forma individual como el equívoco, la unidad fraseológica de uso canónico, la figura retórica: comparación, el pseudoabarcador y la formación de palabras: invención de palabras: creación afijal. Siendo los dos indicadores lingüísticos más productivos el equívoco y el uso de fraseología.

Entre los mecanismos lógicos que detectan la incongruencia, el más recurrente es el razonamiento correcto, desde premisas falsas. Pero también encontramos otros como razonamientos imperfectos basados en la exageración, la falsa analogía y el cratilismo.

En cuanto a la infracción de los principios conversacionales, hemos observado que se incumplen todos ellos: Informatividad, Manera y Cantidad. Aunque el más usual es el de Informatividad, puesto que el humor juega con la ambigüedad y otros mecanismos semánticos. Los otros dos principios, el de Manera y el de Cantidad, se quedan supeditados al de Informatividad. En la siguiente figura podemos ver cómo se relacionan dichos principios con los indicadores lingüísticos analizados. 


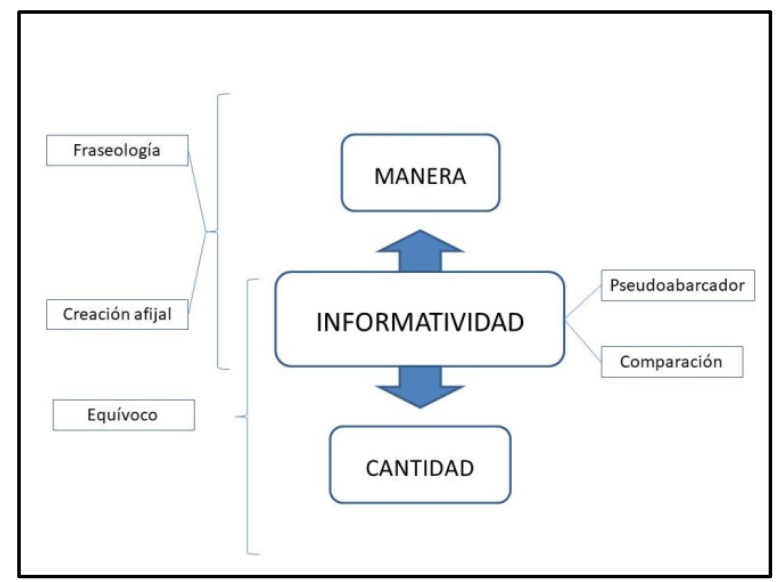

FIGURA 8: Relación entre principios conversacionales e indicadores lingüísticos.

El principio de Informatividad ocupa el lugar central, puesto que en todas las secuencias analizadas aparece la infracción de dicho principio. De este modo, el incumplimiento del principio de Manera y de Cantidad quedaría en una posición subordinada. Aquellos indicadores que juegan con la ambigüedad semántica como son el pseudoabarcador y la figura retórica: comparación, se relacionan directamente con la infracción del principio de Informatividad. Sin embargo, aquellos indicadores que marcan el discurso como son las unidades fraseológicas de uso canónico y la creación afijal, se relacionan tanto con la infracción del principio de Manera como con el de Informatividad, ya que, por un lado, se marca el discurso de forma humorística y, por otro, se realiza un juego semántico con el doble significado, literal e idiomático, en las expresiones fraseológicas; o se combinan los significados de una base léxica y un sufijo para crear un nuevo término con efecto cómico en la creación afijal. Los indicadores lingüísticos que ocultan información como es el equívoco, se relacionan directamente con la infracción del principio de Cantidad, pues no se ofrece toda la información que el oyente necesita. Dicha ocultación hace que se cree ambigüedad, con lo que también está relacionado con la infracción del principio de Informatividad.

Por último, la comedia de situación es un género cuya finalidad es que el espectador ría en intervalos de tiempo breves. De ahí que haya más secuencias humorísticas orientadas exclusivamente al espectador. En estos casos, los personajes de la ficción no ríen; sin embargo, sí se escucha las risas enlatadas, cuya función es orientar al oyente para detectar el giro humorístico.

En la siguiente figura, FIGURA 9, podemos ver las conclusiones resumidas. 


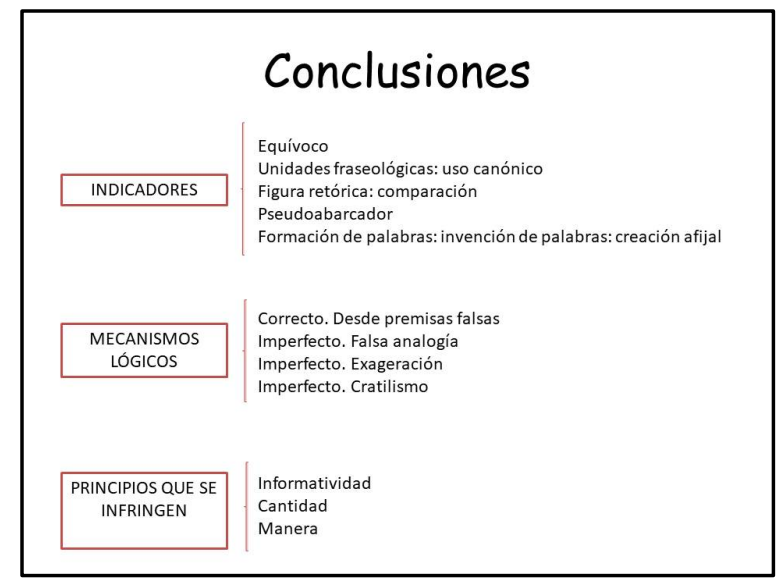

FIGURA 9: Cuadro - resumen conclusiones

Para finalizar, nos parece conveniente señalar que este artículo es parte de una investigación en curso donde nuestro objetivo es analizar los mecanismos que se utilizan para conseguir el efecto humorístico en las comedias de situación y obtener un patrón generalizable a otros textos similares.

\section{BIBLIOGRAFÍA}

Aliaga Aguza, Laura M. ${ }^{a}$ (2013): «Acercamiento pragmático al humor verbal en el género audiovisual: la comedia de situación Cómo conocí a vuestra madre», en Alvarado Ortega, $\mathrm{M}^{\mathrm{a}}$ Belén y Leonor Ruiz Gurillo, coords., Humor, Ironía y Géneros Textuales, Alicante, Servicio de Publicaciones de la Universidad de Alicante, 11-39.

Aliaga Aguza, Laura M. a (2014): «Mecanismos de humor visual en la comedia de situación Cómo conocí a vuestra madre», en ELUA, Estudios de Lingüística de la Universidad de Alicante, 29, 7 38, http://dx.doi.org/10.14198/ELUA2014.28.01

Aliaga Aguza, Laura M. ${ }^{a}$ (2017): "La estrategia narrativa como recurso humorístico en la comedia de situación. El caso de Cómo conocí a vuestra madre", en ELUA, Estudios de Lingüística de la Universidad de Alicante, 31, 925 , http://dx.doi.org/10.14198/ELUA2017.31.01

Alvarado Ortega, M. ${ }^{a}$ Belén y Leonor Ruiz Gurillo, coords. (2013): Humor, Ironía y Géneros Textuales, Alicante, Servicio de Publicaciones de la Universidad de Alicante.

Attardo, Salvatore (2008): «A primer for the linguistics of humor», en Raskin, Victor, ed., The Primer of Humor Research, Berlin, Mouton de Gruyter, 101-155.

Attardo, Salvatore et alii (2002): «Script oppositions and logical mechanisms: Modelling incongruities and their resolutions", Humor, 15, 1, 3-46.

Attardo, Salvatore y Victor Raskin (1991): «Script theory revis(it)ed: Joke similarity and joke representation model», Humor, 4 (3-4), 293347, https://doi.org/10.1515/humr.1991.4.34.293

Gallud Gardiel, Enrique (2016): Teoría y mecanismos del humor, Madrid, Editorial Carpe Noctem.

Grandío Pérez, M. ${ }^{a}$ Mar y Patricia Diego González (2009): "La influencia de la sitcom americana en la producción de comedias televisivas en España. El caso de 'Friends' y '7 Vidas'”, Ámbitos, 18, 83-97.

Levinson, Stephen C. (2004 [2000]): Significados presumibles: la teoría de la implicatura conversacional generalizada, Gredos, Madrid.

Martínez Sierra, Juan José (2008): Humor y traducción. Los Simpson cruzan la frontera, Universitat Jaume I, Castelló.

Padilla García, Xose Antonio (2009): "Marcas acústico-melódicas: el tono irónico», en Ruiz Gurillo, Leonor y Xose Antonio Padilla García, eds., Dime cómo ironizas y te diré quién eres. Una aproximación pragmática a la ironía, Frankfurt, Peter Lang, 135-166.

Padilla García, Xose Antonio y Elvira Gironzetti (2010): «Humor e ironía en las viñetas cómicas periodísticas: un estudio pragmáticointercultural», en Foro hispánico: revista hispánica de Flandes y Holanda, 44, 93-133, https://doi.org/10.1163/9789401208772_006

Platas Tasende, Ana M. ${ }^{a}$ (2004): Diccionario de terminus literarios, Madrid, Espasa.

Raskin, Victor (1985): Semantic Mechanisms of Humor, Reidel, Dordrecht.

Ruiz Gurillo, Leonor (2001): Las locuciones en español actual, Madrid, Arco/Libros. 
Estudio lingüístico de los indicadores del humor | Laura Aliaga

Ruiz Gurillo, Leonor (2012): La lingüística del humor en español, Madrid, Arco/Libros.

Ruiz Gurillo, Leonor y Xose Antonio Padilla García, eds. (2009): Dime cómo ironizas y te diré quién eres. Una aproximación pragmática a la ironía, Frankfurt, Peter Lang.
Timofeeva, Larisa (2012): El significado fraseológico. En torno a un modelo explicativo y aplicado, Madrid, Ediciones Liceu.

Verschueren, Jef (2002): Para entender la pragmática, Gredos, Madrid. 